\title{
Modelling of a Dual Circuit Induced Draft Cooling Water System for Control and Optimisation Purposes ${ }^{\text {负 }}$
}

\author{
C.J. Muller ${ }^{\mathrm{a}, \mathrm{b}}$, I.K. Craigh,* \\ ${ }^{a}$ Sasol, Sasolburg, South Africa. \\ ${ }^{b}$ Department of Electrical, Electronic, and Computer Engineering, University of Pretoria, \\ Pretoria, South Africa.
}

\begin{abstract}
The successful operation of any petrochemical plant is dependent on the use of several utilities which may include electricity, steam, compressed air, cooling media, refrigeration media, nitrogen, condensate and fuel gas. These utilities form a significant portion of the fixed cost associated with running a plant. Utility optimisation has not received much attention until recently, driven by rising energy costs, stricter environmental policies, more competitive markets, and the threat of climate change. The generation, preparation, and transportation of utilities require energy and therefore should be optimised to reduce losses and improve operating efficiency. One example of such a utility is a cooling water system. This paper describes the modelling of a dual circuit induced draft cooling water system for control and optimisation purposes. The derived model is verified with plant data indicating promising results. The model is represented in a steady-state algebraic form as well as a dynamic state-space form. This provides a convenient basis for simulation studies and controller/optimiser design.
\end{abstract}

Keywords: Modelling, verification, optimisation, energy, hybrid systems

\footnotetext{
${ }^{2}$ A preliminary version of this article was presented at the $19^{\text {th }}$ IFAC World Congress, Cape Town, 2014 [1].

*Corresponding author. Tel.: +27 124202172 .

Email addresses: nelis.muller@sasol.com, nelismuller@tuks.co.za (C.J. Muller), icraig@postino.up.ac.za (I.K. Craig)
}

Preprint submitted to Journal of Process Control

November 4, 2014 


\section{Introduction}

There has been a recent revival in the focus on operating efficiency improvement in the process industry stimulated by rising energy costs, stricter environmental policies, struggling global markets, and the threat of climate change 5 [2]. Most of the current energy optimisation efforts focus on power generation, the mining sector, paper and pulp plants, cement factories, smelting furnaces, renewable sources, and the smart grid concept with an apparent lack in focus on the petrochemical industry. Although historically product margins far outweighed the cost of additional energy input for running a plant inefficiently, the situation has changed recently with the margin between energy cost and product recovery decreasing. Therefore, a different approach to energy management is required.

The petrochemical industry accounts for a significant portion of energy usage and greenhouse gas emission globally. Therefore, a seemingly insignificant efficiency improvement in this domain can substantially impact global energy consumption and emissions. From a financial point of view, energy costs in refineries in the U.S. are approximated at between $50 \%$ and $60 \%$ of total fixed cost and at $30 \%$ to $40 \%$ for chemical plants [3]. In South Africa, the petrochemical industry was responsible for more than $20 \%$ of electricity consumption in manufacturing between 1993 and 2006 4. Therefore, the potential for considerable savings exits by reducing energy consumption in this industry. Furthermore, many countries are introducing carbon emission taxes with significant financial impact on the process industry.

In some cases plants are designed with energy efficiency in mind, for instance 25 by using process-to-process heat exchangers for heat integration. This can have large long-term benefits though it requires additional capital investment and results in complex process dynamics which complicates operation. In general the opposite is true and the opportunities for optimisation after commissioning can be attractive as described e.g. in [5] and [6].

Energy is transferred to and from a plant mostly through the use of utilities 
such as steam, tempered water, compressed air, electricity, fuel gas, cooling water, etc. and a reduction in the consumption of these utilities results in a direct energy saving. A less frequently considered improvement area is the supply or generation side of these utilities. The amount of energy lost in the generation and transmission of utilities is considerable [7, 8]. Furthermore, poor focus on control of these utilities results in running unnecessarily large buffer capacities which typically results in additional waste through venting or purging to get rid of over-generation at times of stable operation. Therefore, a control and optimisation scheme focussing on the optimal generation and

40 supply of utilities has definite value-adding potential. This paper describes the modelling of a dual circuit induced draft cooling water system for control and optimisation purposes which is a prime example of the opportunities that exist with utilities. A concise non-linear steady-state model is developed that can be used for simulation and real-time optimisation purposes. Thereafter, a dynamic model is derived from the steady state model to be used for dynamic regulation by adding dynamics to key process variables.

\section{Process Description}

Energy is required to move material through a plant and to change its energy content. Energy is added and removed through equipment such as heat exchangers which can easily be modelled through well known heat exchange equations [9]. Energy is also required to transport the media through a plant by using pumps, fans, compressors, blowers, etc. The energy consumption of such equipment can be modelled through duty equations or power curves.

A cooling water system is a prime example of a utility system using a combination of several pumps, fans, and heat exchangers. There are several types of cooling towers including natural draft, mechanical draft, and evaporative condensers. Mechanical draft towers are further classified as induced or forced draft, either of which can be cross-flow or counter-flow [10]. Modelling of cooling towers from first principles is more involved and a simplified model is desirable 
for the purposes of control and optimisation.

The cooling water system modelled in this paper is shown in Figure 1 and is an example of a dual circuit cooling water system with induced draft counterflow cooling towers. There are two water circuits. The first is the tempered water (TW) circuit which is a closed, treated water loop that is pumped by a bank of pumps through the plant heat exchanger network to cool the process and then through another bank of heat exchangers where it transfers the energy to the second circuit, the cooling water $(\mathrm{CW})$ circuit. The cooling water is then pumped by another bank of pumps to a bank of cooling towers (CTs) where it is cooled mainly through partial evaporation as the water interacts with a counter-current induced air draft. This latent heat transfer accounts for about $80 \%$ of heat transfer with the balance occurring through sensible heat transfer between the water and air 9]. The tempered water circuit has a temperature control valve that bypasses the $\mathrm{CW}$ heat exchanger bank if too much cooling is provided (such as during plant load reduction or a sudden rain spell affecting the heat duty of the plant). The pumps on the cooling water side are each equipped with a discharge pressure control valve which will throttle back if the discharge pressure of a pump drops too low. The CW circuit also has side stream filters and a water make-up line which are not shown in Figure 1.

The controlled variables for the system include the TW supply temperature so $\left(T_{T W S}\right)$, the TW differential temperature $\left(\Delta T_{T W}\right)$ (related to the flowrate and plant duty), and the energy consumption of the pumps and fans $\left(W_{T}\right)$. Typical disturbances associated with this system include ambient temperature $\left(T_{a}\right)$ fluctuations, plant load changes, and equipment failures. The available handles for control in the system are the running signals on the pumps and fans, the discharge valves on the cooling water pumps, and the temperature valve on the tempered water circuit (discussed in more detail in Section 4). There are no variable speed drives (VSDs) on this specific process.

This system presents a number of energy optimisation opportunities:

- Each pump can be individually optimised based on the required flow rate 


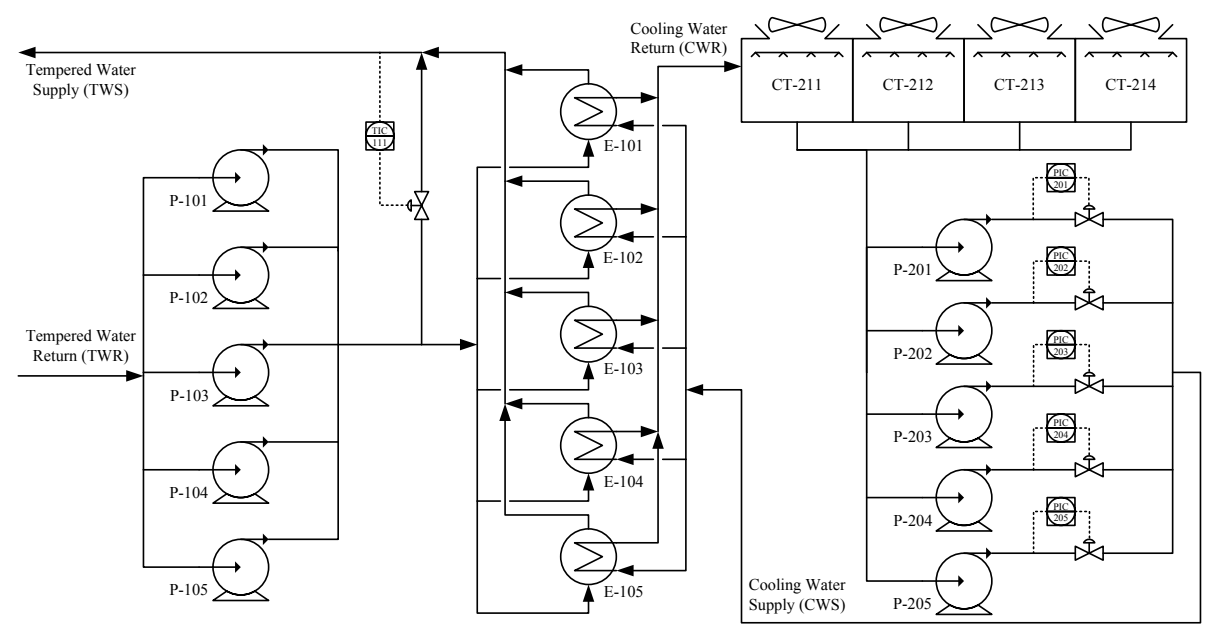

Figure 1: Dual circuit induced draft counter-flow cooling water system. through it.

- Each pump bank can be optimised based on the amount of pumps required to run to ensure that the total circuit flow requirement is met.

- Each circuit can be optimised based on the required flow and temperature of the water.

- The bank of cooling towers can be optimised with regard to the number of fans running and the temperature of the water exiting the towers.

The amount of optimisation is restricted by the following system constraints:

- The maximum flow through a TW pump (P-101 to P-105) is $2500 \mathrm{t} / \mathrm{h}$.

- The maximum flow through a CW pump (P-201 to P-205) is $2750 \mathrm{t} / \mathrm{h}$.

- The TW supply temperature, $T_{T W S} \geq 26^{\circ} \mathrm{C}$.

- The TW differential temperature, $\left(T_{T W R}-T_{T W S}\right) \leq 10^{\circ} \mathrm{C}$.

The lower bound on the TW supply temperature is there for several reasons. One is that the products of this specific production plant can polymerise if the 
TW temperature is too low. A second is that some of the equipment (for exam-

temperature is much lower than design. Violations of this lower bound occur when the temperature controller is unable to adequately increase the temperature and no manual action is taken to this effect (for example by reducing the CW flow by switching a CW pump off). to the heat exchangers, the better the efficiency of heat transfer. Therefore, over-cooling of either circuit is not desirable. If downstream processes are temperature controlled, increasing the temperature of the tempered water will cause higher tempered water flow which will counter the initial intent of reduced energy consumption through reduced cooling tower fan operation and cooling water flow. Therefore, the optimal balance between flow and temperature must be determined to meet the cooling requirements of the plant in the most cost effective way.

\section{Hybrid Systems}

120

The cooling water system described above is a typical example of a hybrid energy system (sometimes referred to as mixed-integer or mixed logical dynamical systems) where there is a combination of continuous and discrete system inputs. The continuous inputs in this case include the control valves whereas the discrete inputs include the pump and fan running statuses. The presence of [11.

Hybrid systems can be dealt with in two distinct layers. The bottom layer is concerned with the continuous process and the top layer with the discrete process. This allows for the use of continuous optimisation for the bottom layer and discrete optimisation for the top layer [12, 13, 14].

In some processes, however, the distinction between layers cannot easily be made due to the level of integration. Therefore, the need arose for a systematic 
way of modelling and designing controllers for hybrid systems that combines the continuous and discrete functions. In [11, the use of mixed integer quadratic programming (MIQP) is suggested with the process described in terms of linear inequalities which are obtained though manipulation of combinational logic. These inequalities, combined with the continuous process model are used to formulate a Model Predictive Control (MPC) solution.

\section{Model Derivation}

A model of the system described in Section 2 has been derived and validated against plant data. The model provides a framework for future control and energy optimisation studies. A simulation using the model provides a baseline for how the plant is normally run with all (or most) pumps and fans running continuously, except when a failure occurs. Control is performed with a temperature controller on the TW side and pressure controllers on the discharges of the CW pumps. All of these are constraint handling controllers with the constraints not being active during normal operation. The temperature controller will only open the heat exchanger bypass valve in the event of too much cooling (a too low TW supply temperature which would result in operational difficulties). The discharge pressure controllers will only throttle back on the discharge valves in the event of the discharge pressure of a pump dropping (i.e. the pump is in danger of running over capacity in terms of flow). These valves were not included in the model. A list of the model constants and typical values are given in Table 1 though some will be repeated in the text for improved readability.

155 The modelling is performed under the following simplifying assumptions:

- Pumps on a bank are identical and balanced in the sense that they get the same feed.

- The cooling towers are identical and balanced in the sense that they get the same feed. 
Table 1: Model parameters

\begin{tabular}{|c|c|c|c|}
\hline Variable & Description & Typical Value & Units \\
\hline$\tau_{T V}^{f}$ & Temperature Valve flow dynamic time constant & $1 / 60$ & $\mathrm{~h}$ \\
\hline$\tau_{T W I}^{f}$ & TW intermediate flow dynamic time constant & $1 / 60$ & $\mathrm{~h}$ \\
\hline$\tau_{T W I}^{T}$ & TW intermediate temperature dynamic time constant & $3 / 60$ & $\mathrm{~h}$ \\
\hline$\tau_{T W S}^{T}$ & TW supply temperature dynamic time constant & $3 / 60$ & $\mathrm{~h}$ \\
\hline$\tau_{T W R}^{T}$ & TW return temperature dynamic time constant & $20 / 60$ & $\mathrm{~h}$ \\
\hline$\tau_{C W}^{f}$ & CW flow dynamic time constant & $1 / 60$ & $\mathrm{~h}$ \\
\hline$\tau_{C W S}^{T}$ & CW supply temperature dynamic time constant & $5 / 60$ & $\mathrm{~h}$ \\
\hline$\tau_{C W R}^{T}$ & CW return temperature dynamic time constant & $6 / 60$ & $\mathrm{~h}$ \\
\hline$P_{s}^{T W}$ & TW pump suction pressure & 230 & $\mathrm{kPa}-\mathrm{g}$ \\
\hline$P_{s}^{C W}$ & CW pump suction pressure & 20 & $\mathrm{kPa}-\mathrm{g}$ \\
\hline$R H$ & Relative humidity & 15 & $\%$ \\
\hline$K_{T W}$ & TW pump head correction factor & 0.90 & - \\
\hline$K_{C W}$ & CW pump head correction factor & 0.90 & - \\
\hline$\nu$ & Vapour fraction CW flow for evaporative flow estimation & 0.00153 & $\% /{ }^{\circ} \mathrm{C}$ \\
\hline$\alpha$ & Approach of the cooling towers & 4.5 & ${ }^{\circ} \mathrm{C}$ \\
\hline$\lambda$ & Heat of vaporisation (for water in this case) & 2260 & $\mathrm{~kJ} / \mathrm{kg}$ \\
\hline$C_{p}$ & Specific heat (for water in this case) & 4.18 & $\mathrm{~kJ} / \mathrm{kg} \cdot{ }^{\circ} \mathrm{C}$ \\
\hline$C_{T V}$ & Flow coefficient of the temperature valve & 2000 & - \\
\hline$C_{E T W}$ & Flow coefficient of the exchanger, TW side & 570 & - \\
\hline$C_{E C W}$ & Flow coefficient of the exchanger, $\mathrm{CW}$ side & 300 & - \\
\hline$C_{C T}$ & Flow coefficient of a single cooling tower & 220 & - \\
\hline$C_{G}$ & Flow coefficient of the plant heat exchanger network & 570 & - \\
\hline$\rho$ & Specific gravity (for water in this case) & 1 & $\mathrm{t} / \mathrm{m}^{3}$ \\
\hline$g$ & Gravitational constant & 9.81 & $\mathrm{~m} / \mathrm{s}^{2}$ \\
\hline$A$ & Heat exchanger area & 100 & $\mathrm{~m}^{2}$ \\
\hline$U$ & Heat exchanger heat transfer coefficient & 330 & $\mathrm{MJ} / \mathrm{h} . \mathrm{m}^{2} \cdot{ }^{\circ} \mathrm{C}$ \\
\hline$W_{C T}$ & $\mathrm{CT}$ fan rated power & 150 & $\mathrm{~kW}$ \\
\hline$c_{c}$ & Concentration cycles for CW circulation & 3 & - \\
\hline
\end{tabular}


- The plant heat exchanger network has a constant flow coefficient (i.e. a constant system curve).

- No switching of heat exchangers occurs (a constant number of heat exchangers are in use all the time).

- Side-stream filters and the dosing system are omitted from the model.

- The suction pressure of the TW pumps is fixed at $230 \mathrm{kPa}-\mathrm{g}$.

- The suction pressure of the $\mathrm{CW}$ pumps is fixed at $20 \mathrm{kPa}-\mathrm{g}$ (i.e. a $2 \mathrm{~m}$ water level in the cooling towers).

- Heat addition by the pumps is negligible.

- Heat exchange with surroundings is negligible.

These assumptions are aimed at finding a balance between model accuracy and complexity and to keep the number of variables and equations reasonable [15].

As suggested in Section 2, the model inputs are

- the pump running signals, $u_{i}^{T W}(t) \in\{0,1\}$ and $u_{j}^{C W}(t) \in\{0,1\}$,

- the CT fan running signals, $u_{k}^{C T}(t) \in\{0,1\}$, and

- the temperature control valve (TV) opening $\left(O P_{T V}\right)$

with $i=1 \ldots n_{T W}, j=1 \ldots n_{C W}$, and $k=1 \ldots n_{C T}$ where $n_{T W}$ and $n_{C W}$ represent the numbers of $\mathrm{TW}$ and $\mathrm{CW}$ pumps and $n_{C T}$ is the number of $\mathrm{CT}$ fans. To reduce the number of input variables, the binary running signals are grouped together into discrete integer signals representing the number of pumps or fans running such that $U_{T W}(t)=\sum_{i=1}^{n_{T W}} u_{i}^{T W}(t), U_{C W}(t)=\sum_{j=1}^{n_{C W}} u_{j}^{C W}(t)$, and $U_{C T}(t)=\sum_{k=1}^{n_{C T}} u_{k}^{C T}(t)$

The model disturbance variables include 
- the plant duty, $Q_{P}(t)(\mathrm{MJ} / \mathrm{h})$,

- the ambient air wet-bulb temperature, $T_{w b}(t)\left({ }^{\circ} \mathrm{C}\right)$,

- the make-up water flow to the cooling towers, $f_{m u}(t)(\mathrm{t} / \mathrm{h})$, and

- the availability of the pumps, fans, and heat exchangers.

The controlled outputs are

- the TW supply temperature, $T_{T W S}$,

- the TW differential temperature $\left(T_{T W R}-T_{T W S}\right)$,

- the electricity consumption of the system, and

- the energy cost of the system.

The first two outputs are for constraint handling whereas the last two can be used for optimisation.

\subsection{Pump Calculations}

The pump operating points are estimated using the pump performance curves and the system curves. When no throttling element is used (such as a discharge throttling valve), the operating point is the intercept between the pump curve and the system curve. When more than one pump runs in parallel, the flow is distributed between pumps and the slightly higher combined discharge pressure results in a higher total flow. Figure 2 illustrates the operation of a single pump versus two identical pumps in parallel [16 for a system with a constant flow coefficient. When running a single pump, the operating point is at A. When running two pumps in parallel, the combined operating point moves to $\mathrm{B}$ with the operating point per pump illustrated by $\mathrm{C}$. Therefore, the more pumps that are run in parallel, the less the progressive increase in flow becomes.

The pump performance curves can be captured in lookup tables for simulation purposes though it is not ideal for the control/optimisation model. Therefore, polynomial functions were fitted to the pump curves to represent the pump 


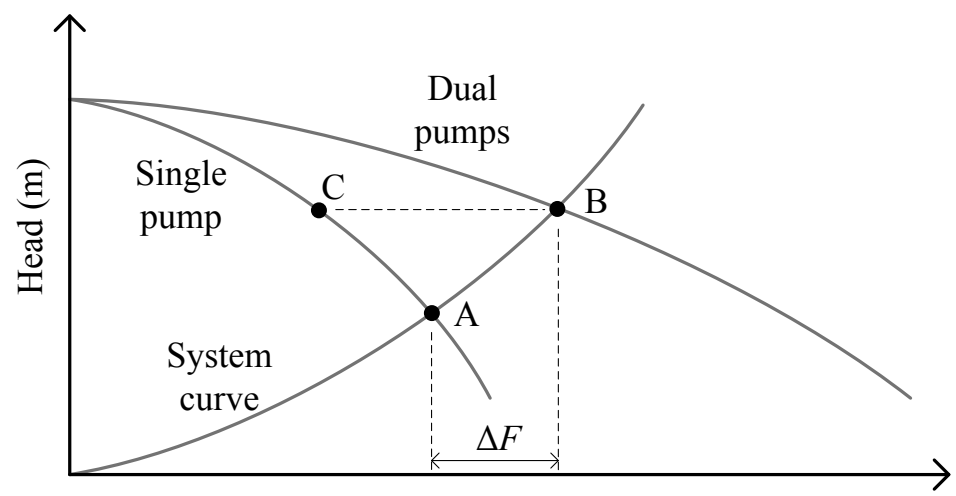

Flow $(\mathrm{t} / \mathrm{h})$

Figure 2: Performance illustration of pumps running in parallel on a system with a constant system curve.

head and power curves. Given a mass flow rate, $f(\mathrm{t} / \mathrm{h})$, the function generates the corresponding head, $h(\mathrm{~m})$, and power $w(\mathrm{~kW})$. The head is translated to discharge pressure, $P_{d}(\mathrm{kPa}-\mathrm{g})$, with $P_{d}=h g \rho+P_{s}$ where $P_{s}$ is the suction pressure $(\mathrm{kPa}-\mathrm{g}), g=9.81 \mathrm{~m} / \mathrm{s}^{2}$ is the gravitational constant, and $\rho=1.0 \mathrm{t} / \mathrm{m}^{3}$ is the specific gravity of water. The full polynomials are given in Section 5

The pump running signals indicate the number of pumps in operation. To simplify the illustration of the flow and duty calculations as described next in Sections 4.2 and 4.3 a simplified process diagram is provided (Figure 3 where the system has been reduced to single pieces of equipment and where key variables are clearly indicated. For the complete model, however, the calculations are done per device and the results combined for the system outputs (see Section 5). The same applies to the cooling tower fan running signals (i.e. a cooling tower is viewed as out of operation if its fan is not running).

\subsection{Flow Calculations}

Figure 3 shows a simplified system diagram indicating the key variables. The flow in the TW circuit is determined by the TW pumps' common discharge pressure $\left(P_{2}\right)$ and the flow coefficients of the plant heat exchanger network, 


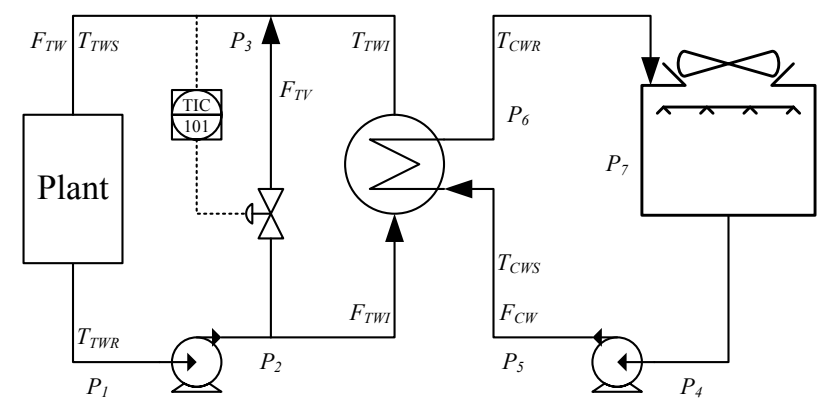

Figure 3: Simplified system representation.

the CW heat exchangers' TW side and the temperature control valve (with valve opening). The flow in the $\mathrm{CW}$ circuit is determined by the $\mathrm{CW}$ pumps' discharge pressure $\left(P_{5}\right)$ and the flow coefficients of the CW heat exchangers' CW side and the cooling towers (the discharge pressure control valves are used as under-pressure controllers only and are omitted from the model). The total flow in the TW circuit is described by

$$
\begin{aligned}
f_{T W} & =f_{T W I}+f_{T V} \\
& =C_{E T W} \sqrt{\frac{\Delta P_{E T W}}{\rho}}+C_{T V} O P_{T V} \sqrt{\frac{\Delta P_{E T W}}{\rho}}
\end{aligned}
$$
and

$$
f_{T W}=C_{G} \sqrt{\frac{\Delta P_{P}}{\rho}}
$$

where $f_{T V}$ is the mass flow through the temperature control valve (TV), $f_{T W I}$ is the intermediate mass flow thought the TW side of the heat exchanger bank, $C_{T V}, C_{E T W}$, and $C_{G}$ are the flow coefficients of the temperature valve, the TW side of the heat exchangers, and the plant, $O P_{T V}$ is the valve opening of the temperature valve, and $\Delta P_{E T W}=P_{2}-P_{3}$ and $\Delta P_{P}=P_{3}-P_{1}$ are differential pressures across the TW side of the heat exchangers (including the 
temperature valve) and across the plant. The differential pressure across the pumps is $\Delta P_{T W P}=P_{2}-P_{1}$ and is determined from the pump curve calculation (see Section 4.1). Furthermore,

$$
\Delta P_{P}=\Delta P_{T W P}-\Delta P_{E T W}
$$

245 and by equating (1) and (2) and substituting for (3) results in

$$
\Delta P_{E T W}=\frac{\Delta P_{T W P}}{\left(\frac{C_{E T W}+C_{T V} O P_{T V}}{C_{G}}\right)^{2}+1}
$$

which allows for the calculation of $f_{T W I}$ and $f_{T V}$. For the CW loop, the flow $f_{C W}$ is calculated in a similar fashion. Here, the combined flow coefficient of the cooling towers is the sum of the flow coefficients of the towers that are in operation.

\subsection{Duty Calculations}

The plant duty, $Q_{P}(\mathrm{MJ} / \mathrm{h})$, is the energy to be removed by the cooling system. This energy is transferred from the plant to the TW stream through the plant heat exchanger network. It is then transferred from the TW to the $\mathrm{CW}$ through the CW heat exchanger bank (shown in Figure 1). The energy is then expelled from the CW stream via the cooling towers. The heat transfer mechanism in the cases for both the plant heat exchanger network and the $\mathrm{CW}$ heat exchangers (assuming no phase change) is sensible heat transfer and is described by

$$
Q=f C_{p} \Delta T
$$

where $f$ is the mass flow of the fluid $(\mathrm{t} / \mathrm{h}), C_{p}$ is the specific heat of the fluid $\left(\mathrm{kJ} / \mathrm{kg}^{\circ} \mathrm{C}\right)$, and $\Delta T$ is the differential temperature between the inlet and the outlet of the heat exchanger $\left({ }^{\circ} \mathrm{C}\right)$. This is valid for both the process and 
utility sides of the exchanger. In this case, both sides are water streams with $C_{p}=4.18 \mathrm{~kJ} / \mathrm{kg}^{\circ} \mathrm{C}$.

The heat exchanger duty is determined by the heat transfer coefficient, $U$ ${ }_{265}\left(\mathrm{MJ} / \mathrm{hm}^{2 \circ} \mathrm{C}\right)$, the heat exchange area, $A\left(\mathrm{~m}^{2}\right)$, and the $\log$ mean temperature difference between the process and utility streams, $\Delta T_{l m}\left({ }^{\circ} \mathrm{C}\right)[9$. With reference to Figure 3 , the heat exchanger duty is described as

$$
\begin{aligned}
Q & =U A \Delta T_{l m} \\
& =U A \frac{\left(T_{T W R}-T_{C W S}\right)-\left(T_{T W I}-T_{C W R}\right)}{\ln \left(\frac{T_{T W R}-T_{C W S}}{T_{T W I}-T_{C W R}}\right)}
\end{aligned}
$$

where $T_{C W S}$ and $T_{C W R}$ are the CW supply and return temperatures, $T_{T W R}$ is the TW return temperature, and $T_{T W I}$ is the TW intermediate temperature (the heat exchanger outlet temperature on the TW side).

By substituting (5) (on the TW side) into (6), $T_{T W I}$ is calculated as

$$
T_{T W I}=\frac{T_{C W S}-\frac{Q}{f_{T W I} C_{p}}-e^{K} T_{C W R}}{1-e^{K}}
$$

with

$$
K=\left(\frac{Q}{f_{T W I} C_{p}}-T_{C W S}+T_{C W R}\right) \frac{U A}{Q} .
$$

The TW supply temperature is then calculated as

$$
T_{T W S}=\frac{T_{T W I} f_{T W I}+T_{T W R} f_{T V}}{f_{T W}}
$$

where $f_{T W I}, f_{T V}$, and $f_{T W}$ are discussed in Section 4.2. Note that when the temperature control valve is closed, $f_{T W}=f_{T W I}$ and therefore $T_{T W S}=T_{T W I}$.

On the CW circuit, a simplified model was used to determine the heat exchange in the cooling towers. This required the wet-bulb temperature $\left(T_{w b}\right)$ of the air. The ambient temperature, $T_{a}$, is measured and used together with 
the relative humidity $(R H)$ measurement to calculate the approximate $T_{w b}$ as follows [17]:

$$
\begin{aligned}
T_{w b} & =T_{a} \tan ^{-1}\left(0.151977(R H+8.313659)^{0.5}\right) \\
& +\tan ^{-1}\left(T_{a}+R H\right)-\tan ^{-1}(R H-1.676331) \\
& +0.00391838\left(R H^{1.5}\right) \tan ^{-1}(0.023101 . R H) \\
& -4.686035
\end{aligned}
$$

The difference between the achievable $T_{C W S}$ and $T_{w b}$ is called the approach $(\alpha)$ and is dependent on the tower design and operating conditions. The amount of water being evaporated in the cooling towers $(\mathrm{t} / \mathrm{h})$ can be estimated as

$$
f_{e}=\nu f_{C W}\left(T_{C W R}-T_{C W S}\right)
$$

and

$$
f_{e}=f_{m u}-f_{b}-f_{d}
$$

where $f_{m u}$ is the make-up water added to the system on CT level control, $f_{b}$ is the blow-down to prevent solids build-up in the system, and $f_{d}$ is the drift loss through splashing and entrainment. Combining the recommendations from [9] and [10] resulted in a vaporisation fraction $\nu=0.00153\left(\% /{ }^{\circ} \mathrm{C}\right), f_{d}=0.001 f_{C W}$ and $f_{b}=f_{e} / 2$ (assuming three cycles of concentration, $c_{c}$ ). Equation 12 can then be used to calculate the approximate $f_{e}$ though it does not contain any reference to the ambient conditions in its current form. Therefore, it is multiplied by the convergence term, $\left(T_{C W S} /\left(T_{w b}+\alpha\right)\right)$, which serves to compensate for ambient condition changes and also takes the approach into account. For example, if $T_{w b}$ drops due to a drop in $R H$, it will result in a higher $f_{e}$ which means more cooling. Equation (11) can now be used to calculate the new value of $T_{C W S}$. The portion of the duty of the CTs due to the partial evaporation is 
calculated as

$$
Q_{e}=f_{e} \lambda
$$

where $\lambda=2260 \mathrm{~kJ} / \mathrm{kg}$ is the approximate heat of vaporisation for water. Having calculated the values for $T_{C W S}$ and $T_{T W S}$, the new values for $T_{C W R}$ and $T_{T W R}$ can be determined with the use of Equation 5

\subsection{Energy Model}

An energy consumption model of the system can be formulated based on the running statuses and power consumptions of the equipment. The running signal of the $i$ th component is denoted by

$$
u_{i}(t)= \begin{cases}1 & \text { for component ON } \\ 0 & \text { for component OFF }\end{cases}
$$

$$
W_{i}(t)=u_{i}(t) w_{i}(t)
$$

where $w_{i}(t)$ is the operating power of the $i$ th component. A simplified model can be constructed by assuming a constant power consumption equal to the rated power per piece of equipment such that

$$
w_{i}(t)=W_{i}^{\max }
$$

where $W_{i}^{\max }$ denotes the rated power of the $i$ th component [14]. In this case, more accurate power consumption data is available from the power curves of the pumps and can be calculated using the fitted polynomial functions (as 
discussed in Section 4.1) and flow rate. The total power consumption at time $t$ is

$$
W_{T}(t)=\sum_{i=1}^{N} W_{i}(t)
$$

with $N=n_{T W}+n_{C W}+n_{C T}$. An objective function for energy optimisation

$$
J_{W}=\int_{t_{0}}^{t_{f}} W_{T}(t) d t
$$

or for energy cost

$$
J_{C}=\int_{t_{0}}^{t_{f}} W_{T}(t) p(t) d t
$$

where $p(t)$ is the electricity price at time $t$. If no TOU tariff is applicable, $p(t)$ reduces to a constant [18.

\section{State-Space Model}

For formulation of control and optimisation solutions for the system as described in Sections 2 and 4 it is advantageous to represent the system in statespace form. Dynamics were added to selected variables to represent the system states whereas others were maintained as algebraic equations. Effort was made to only include the important dynamic behaviours. To lend simplicity to the model, it is assumed that each state variable's transient behaviour is described by a first order dynamic which is the same for all its sources of change (inputs, disturbances, other states, etc.) with the gains differing according to the nonlinear equations discussed in Section 4 
The discrete time state-space model consisting of difference equations and algebraic equations is based on the full system shown in Figure 1 and is derived from the model in Section 4 The states are

$$
\begin{aligned}
& f_{T V}(k+1)=\frac{\Delta t C_{T V}}{\tau_{T V}^{f}} O P_{T V}(k) \sqrt{\frac{\Delta P_{E T W}(k)}{\rho}}+f_{T V}(k)\left(1-\frac{\Delta t}{\tau_{T V}^{f}}\right) \\
& f_{T W I}(k+1)=\frac{\Delta t C_{E T W}}{\tau_{T W I}^{f}} \sqrt{\frac{\Delta P_{E T W}(k)}{\rho}}+f_{T W I}(k)\left(1-\frac{\Delta t}{\tau_{T W I}^{f}}\right) \\
& f_{C W}(k+1)=\frac{\Delta t C_{C T}}{\tau_{C W}^{f}} U_{C T}(k) \sqrt{\frac{\Delta P_{C T}(k)}{\rho}}+f_{C W}(k)\left(1-\frac{\Delta t}{\tau_{C W}^{f}}\right) \\
& T_{T W S}(k+1)=\frac{\Delta t}{\tau_{T W S}^{T}}\left(\frac{T_{T W I}(k) f_{T W I}(k)+T_{T W R}(k) f_{T V}(k)}{f_{T W}(k)}\right)+T_{T W S}(k)\left(1-\frac{\Delta t}{\tau_{T W S}^{T}}\right) \\
& T_{T W R}(k+1)=\frac{\Delta t}{\tau_{T W R}^{T}}\left(\frac{Q_{P}(k)}{f_{T W}(k) C_{p}}+T_{T W S}(k)\right)+T_{T W R}(k)\left(1-\frac{\Delta t}{\tau_{T W R}^{T}}\right) \\
& T_{C W R}(k+1)=\frac{\Delta t}{\tau_{C W R}^{T}}\left(\frac{Q_{P}(k)}{f_{C W}(k) C_{p}}+T_{C W S}(k)\right)+T_{C W R}(k)\left(1-\frac{\Delta t}{\tau_{C W R}^{T}}\right) \\
& T_{C W S}(k+1)=\frac{\Delta t}{\tau_{C W S}^{T}}\left(T_{C W R}(k)-\frac{f_{e}(k)}{f_{C W}(k) \nu}\right)+T_{C W S}(k)\left(1-\frac{\Delta t}{\tau_{C W S}^{T}}\right) \\
& T_{T W I}(k+1)=\frac{\Delta t}{\tau_{T W I}^{T}}\left(\frac{T_{C W S}(k)-\frac{Q_{P}(k)}{f_{T W I}(k) C_{p}}-e^{K(k)} T_{C W R}(k)}{1-e^{K(k)}}\right)+T_{T W I}(k)\left(1-\frac{\Delta t}{\tau_{T W I}^{T}}\right)
\end{aligned}
$$


with algebraic equations

$$
\begin{aligned}
& K(k)=\left(\frac{Q_{P}(k)}{f_{T W I}(k) C_{p}}-T_{C W S}(k)+T_{C W R}(k)\right) \frac{U A}{Q_{P}(k)} \\
& f_{T W}(k)=F_{T V} k+F_{T W I}(k)
\end{aligned}
$$

$\Delta P_{T W P}(k)=k_{T W} h_{T W}(k) \rho g$

$$
\begin{aligned}
& h_{T W}(k)=-\left(7 \times 10^{-6}\right)\left(\frac{f_{T W}(k)}{U_{T W}(k)}\right)^{2}+0.0036 \frac{f_{T W}(k)}{U_{T W}(k)}+88.28 \\
& \Delta P_{E T W}(k)=\frac{\Delta P_{T W P}(k)}{\left(\frac{C_{E T W}+C_{T V} O P_{T V}(k)}{C_{G}}\right)^{2}+1}
\end{aligned}
$$

$\Delta P_{C T}(k)=\frac{\Delta P_{C W P}(k)}{\left(\frac{U_{C T}(k) C_{C T}}{C_{E C W}}\right)^{2}+1}$

$\Delta P_{C W P}(k)=k_{C W} h_{C W}(k) \rho g$

$h_{C W}(k)=-\left(6 \times 10^{-6}\right)\left(\frac{f_{C W}(k)}{U_{C W}(k)}\right)^{2}+0.0005 \frac{f_{C W}(k)}{U_{C W}(k)}+58.30$

$f_{e}(k)=\left(\frac{c_{c}-1}{c_{c}}\right)\left(\frac{f_{m u}(k)}{U_{C T}(k)}-0.001\left(\frac{f_{C W}(k)}{U_{C T}(k)}\right)\right)\left(\frac{T_{C W S}(k)}{T_{W B}(k)+\alpha}\right) U_{C T}(k)$

$Q_{e}(k)=f_{e}(k) \lambda$ 
where $\Delta t$ is the sampling time ( 1 minute in this case) and $T_{W B}(k)$ is obtained from (10). The total power can be written in the form

$$
\begin{gathered}
W_{T}(k)=W_{T W}(k)+W_{C W}(k)+W_{C T}(k) \\
W_{T W}(k)=U_{T W}(k)\left(-\left(2 \times 10^{-5}\right)\left(\frac{f_{T W}(k)}{U_{T W}(k)}\right)^{2}+0.1772 \frac{f_{T W}(k)}{U_{T W}(k)}+131.7\right)
\end{gathered}
$$

$W_{C W}(k)=U_{C W}(k)\left(-\left(8 \times 10^{-9}\right)\left(\frac{f_{C W}(k)}{U_{C W}(k)}\right)^{3}+\left(2 \times 10^{-5}\right)\left(\frac{f_{C W}(k)}{U_{C W}(k)}\right)^{2}+0.0195 \frac{f_{C W}(k)}{U_{C W}(k)}+182.9\right)$

$$
W_{C T}(k)=U_{C T}(k) W_{C T}^{\max }
$$

Therefore, the model has 8 state equations represented by (20) to (27), 14 algebraic equations (of which some are intermediate variables) given by 28 to (41), 4 inputs $\left(U_{T W}(k), U_{C W}(k), U_{C T}(k)\right.$, and $\left.O P_{T V}(k)\right)$ ), and 3 measured (or estimated) disturbances $\left(Q_{P}(k), T_{W B}(k)\right.$, and $\left.f_{m u}(k)\right)$.

\section{Simulation}

The model was verified against plant data for a period of 6 days (144 hours) using a one minute sampling interval and yielded promising results. The data represents a period in which significant duty changes occurred. Initial parameter values were chosen based on design data (where available) and observed response times and are shown in Table 2. Some possible unmeasured disturbances such as heat exchanger isolation ${ }^{1}$, rain events, etc. were not modelled.

\footnotetext{
${ }^{1}$ Isolating a heat exchanger has two disturbance effects: First, it reduces the total heat exchange area which affects the stream temperatures on both circuits. Second, it affects the
} 
The correlation coefficients and squared errors between some of the plant and model outputs were used as a simple measure of similarity between the data sets (i.e. the validity of the model). The modelling was performed under the following limitations:

- Limited switching data for the TW pumps (only a few pump switching activities for the period of validation).

- No switching data for the CT fans (no history data).

- No heat exchanger commissioning/decomissioning data (not measured).

- Limited process measurements on the cooling towers (no air flow or temperature measurement, no pressure measurement on $\mathrm{CW}$ entering cooling towers, etc.).

- No blow-down flow measurement which necessitates its approximation using concentration cycles (see Section 4.3).

- Significant data noise on some variables.

- Inability to step test the actual process.

\subsection{Parameter Estimation}

To improve the model fit, a parameter estimation exercise was performed for several key parameters. These include the flow coefficients $\left(C_{G}, C_{E T W}, C_{E C W}\right.$, $C_{C T}$, and $C_{T V}$ ), the heat exchanger heat transfer coefficient $(U)$, the pump head correction factors $\left(K_{T W}\right.$ and $\left.K_{C W}\right)$, and the temperature time constants $\left(\tau_{T W S}^{T}, \tau_{T W R}^{T}, \tau_{C W S}^{T}, \tau_{C W R}^{T}\right.$, and $\left.\tau_{T W I}^{T}\right)$. The optimisation was done in two parts. For the first part the performance function was set equal to the sum of the TWS, TWR, and duty correlation coefficients for the total simulation period. This was used mainly to determine the time constant values. For the second

flow coefficient of the heat exchanger bank (on both the TW and CW sides) and therefore affects the flow rates in both circuits. 
Table 2: Optimised model parameters

\begin{tabular}{lrr} 
Parameter & Initial & Optimised \\
\hline$C_{G}$ & 570 & 417 \\
$C_{E T W}$ & 570 & 737 \\
$C_{E C W}$ & 300 & 237 \\
$C_{C T}$ & 220 & 353 \\
$C_{T V}$ & 2000 & 820 \\
$U$ & 330 & 509 \\
$K_{T W}$ & 0.90 & 0.90 \\
$K_{C W}$ & 0.90 & 0.58 \\
$\tau_{T W S}^{T}$ & $3 / 60$ & $3.87 / 60$ \\
$\tau_{T W R}^{T}$ & $20 / 60$ & $20.96 / 60$ \\
$\tau_{C W S}^{T}$ & $5 / 60$ & $3.47 / 60$ \\
$\tau_{C W R}^{T}$ & $6 / 60$ & $8.25 / 60$ \\
$\tau_{T W I}^{T}$ & $3 / 60$ & $4.86 / 60$ \\
\hline
\end{tabular}

part the performance function was an error squared formulation looking at the errors between the simulated and plant data for the TW supply temperature and the TW differential temperature. Upper and lower bounds were specified for each parameter. A genetic algorithm was chosen for the optimisation due to its ability to handle non-linear, discontinuous, multi-parameter problems and its likelihood of finding a global optimum [19, 20, 21]. The MATLAB ga function was used with a population size of 20 . The algorithm was tested with supplied initial conditions as well as allowing it to create its own initial population. The latter provides more randomness to iterations of the optimisation problem which further alleviates the possibility of converging on a local optimum. With a randomly selected initial population, the algorithm typically converges after 15 to 20 generations. The optimised parameter values are given in Table 2 


\subsection{Results}

Figure 4 shows the data inputs to the model for $Q_{P}(t)$ (calculated using (5)) and $T_{w b}(t)$ (calculated using 10 with the measured ambient temperature and humidity). Other inputs include $U_{T W}(t), U_{C W}(t), U_{C T}(t)$, and $f_{m u}(t)$. Figure 5 shows the model response (solid line) versus the plant data (dotted line) for $T_{T W R}(t)$ and $T_{T W S}(t)$. An analysis of the results indicates that the evaporative duty, $Q_{e}(t)$ (calculated using (13)), is indeed approximately $80 \%$ of total duty as stated in Section 2 .
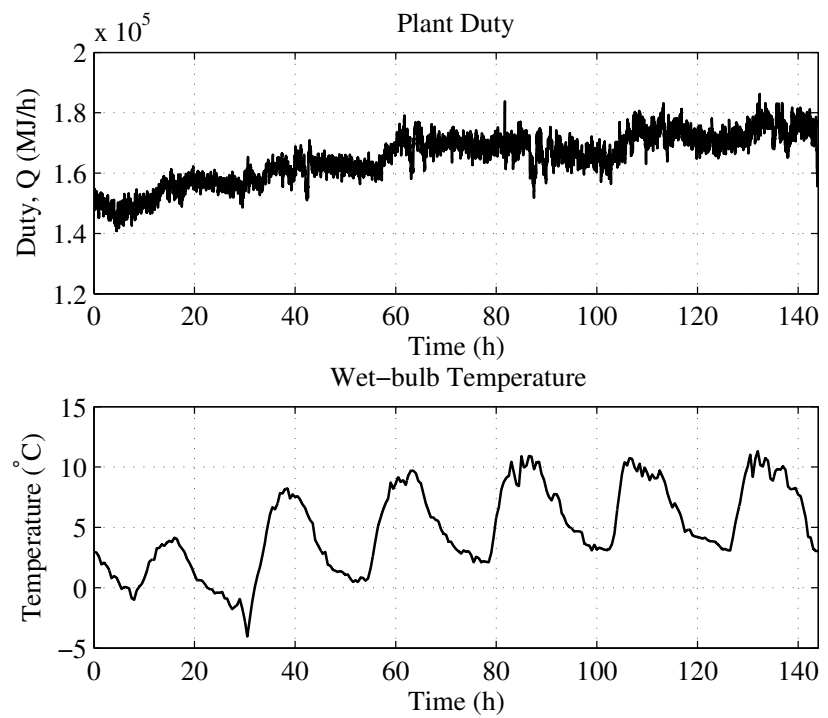

Figure 4: Model disturbance inputs.

The correlation coefficients for $T_{T W R}(t), T_{T W S}(t), \Delta T_{T W}(t)$ and $Q_{e}(t)$ are shown in Table 3 .

To illustrate the behaviour of the model, some steps were made in the input and disturbance variables and the resulting effects observed on some process variables. These are shown in Fugures 6 to 9 in a model matrix format. The manipulated variables represent the columns of the model matrices and the process variables the rows. One manipulated/disturbance variable was changed at a time while keeping the others constant at nominal values. The stepping 


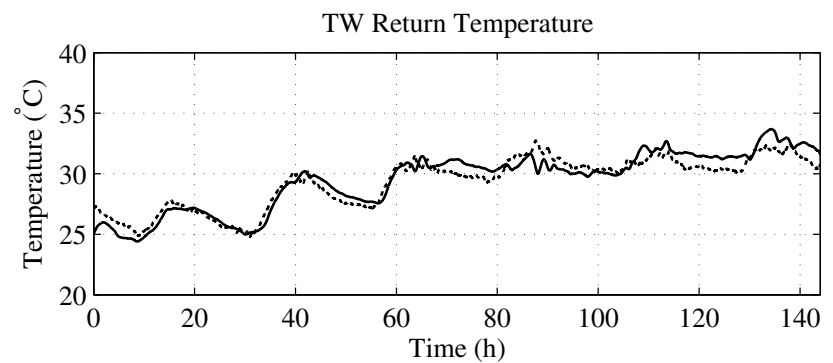

TW Supply Temperature

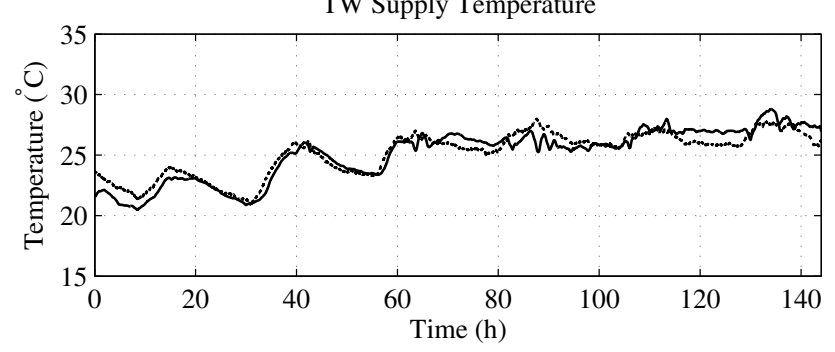

Figure 5: Model TW results (model response (solid line) versus the plant data (dotted line)).

was done over a period of 10 hours in each case starting from steady-state conditions. The scales on the vertical axes were kept constant across each row to illustrate the relative sizes of the responses. The process variables observed are the TW flow $\left(f_{T W}\right)$, CW flow $\left(f_{C W}\right)$, TW supply temperature $\left(T_{T W S}\right)$, CW supply temperature $\left(T_{C W S}\right)$, total power $\left(W_{T}\right)$, and the TW differential temperature $\left(\Delta T_{T W}\right)$. In Figures 6 and 7 , the responses are shown for changes in the TW pump running signals $\left(U_{T W}\right)$, CW pump running signals $\left(U_{C W}\right)$, and the $\mathrm{CT}$ fan running signals $\left(U_{C T}\right)$ whereas Figures 8 and 9 show the responses to changes in the temperature control valve opening $\left(O P_{T V}\right)$, plant duty $\left(Q_{P}\right)$, and ambient temperature $\left(T_{a}\right)$.

The responses confirm that the model behaves as expected and reveals some interesting dynamics and interactions. It is clear from Figures 6 and 8 how the progressive increase in flowrate decreases as more pumps are brought on line for pumps running in parallel. It also illustrates that, although the temperature control valve has a linear characteristic, the installed characteristic is non-linear as it interacts with the system. It is clear that the strongest handle on the TW 

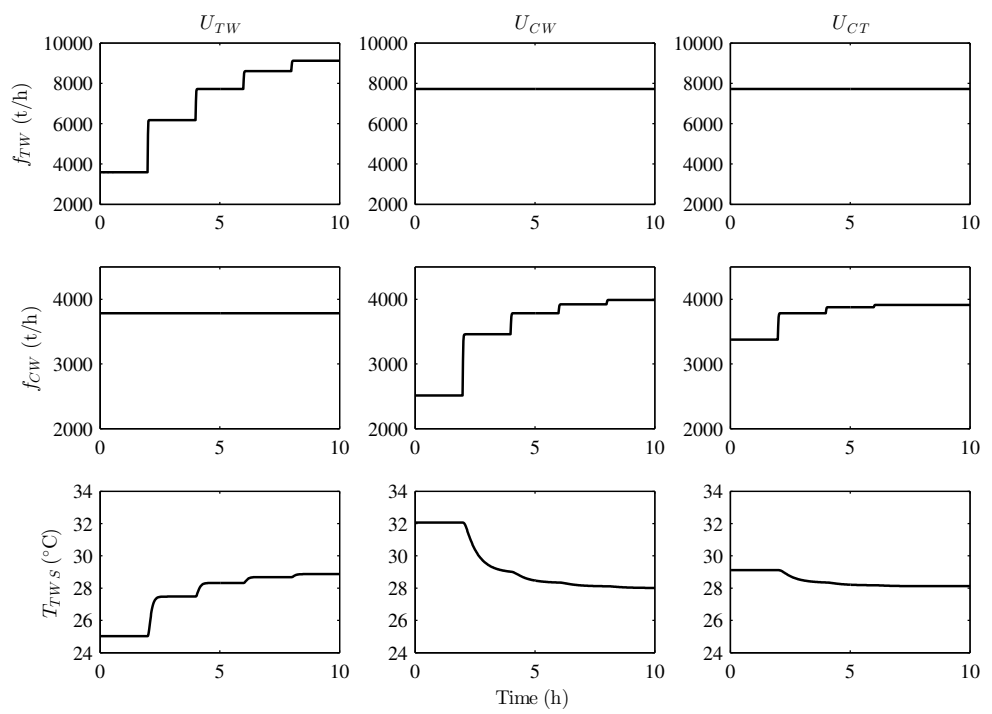

Figure 6: Responses in $f_{T W}, f_{C W}$, and $T_{T W S}$ to changes in $U_{T W}, U_{C W}$ and $U_{C T}$.
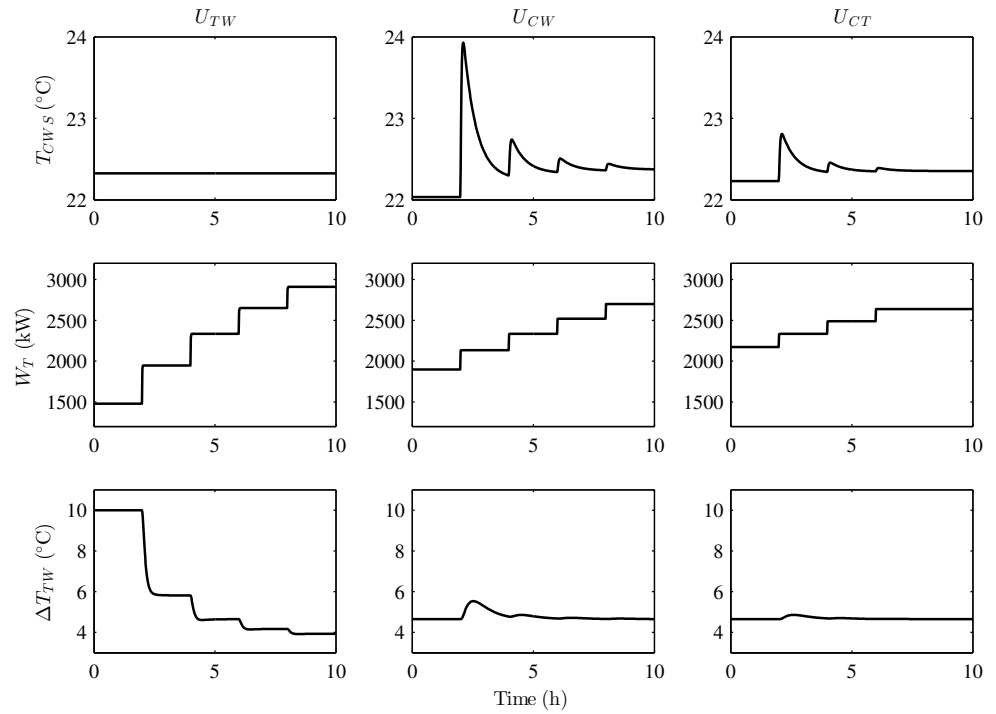

Figure 7: Responses in $T_{C W S}, W_{T}$, and $\Delta T_{T W}$ to changes in $U_{T W}, U_{C W}$ and $U_{C T}$. 

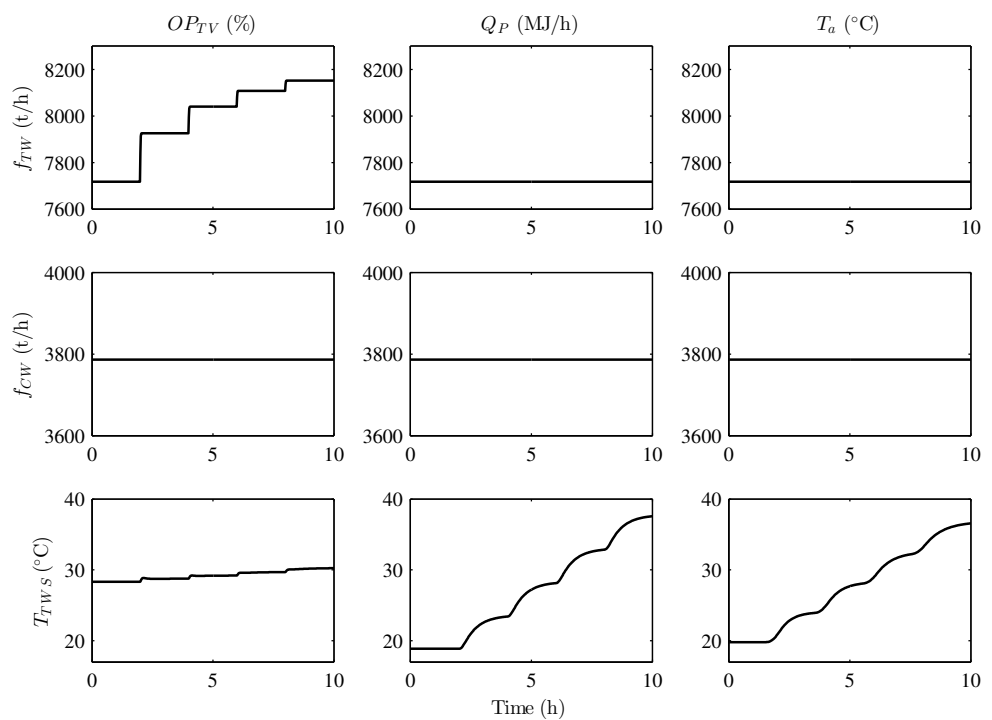

Figure 8: Responses in $f_{T W}, f_{C W}$, and $T_{T W S}$ to changes in $O P_{T V}, Q_{P}$ and $T_{a}$.
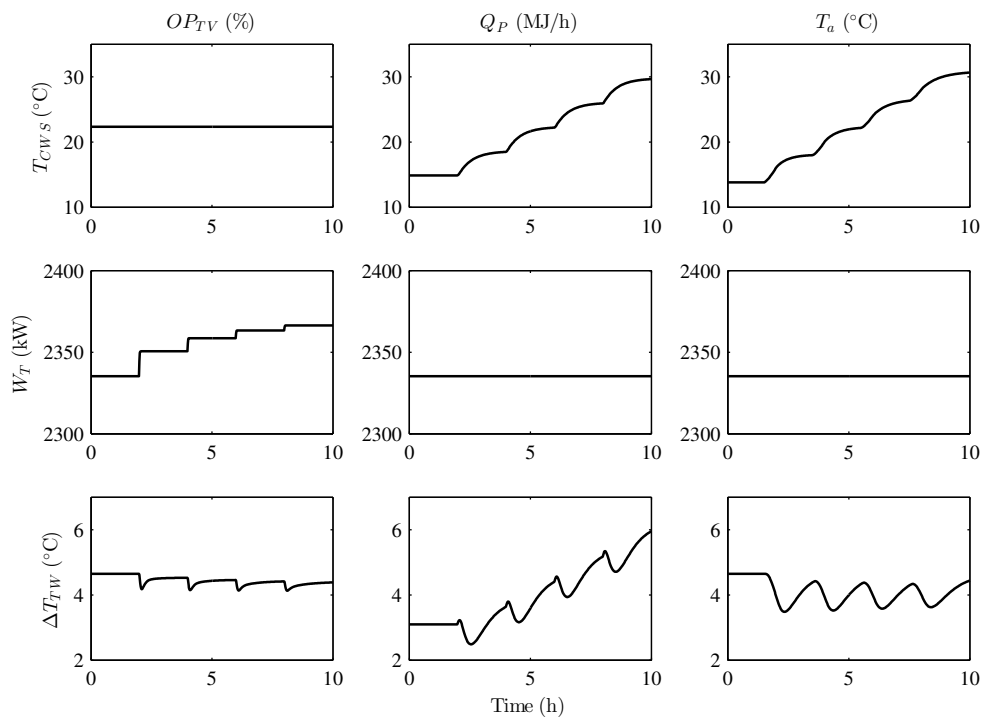

Figure 9: Responses in $T_{C W S}, W_{T}$, and $\Delta T_{T W}$ to changes in $O P_{T V}, Q_{P}$ and $T_{a}$. 
Table 3: Model correlation coefficients with and without parameter estimation

\begin{tabular}{llr} 
Variable & Initial & Optimised \\
\hline$T_{T W R}(t)$ & 0.6182 & 0.9511 \\
$T_{T W S}(t)$ & 0.4968 & 0.9429 \\
$Q_{e}(t)$ & 0.9020 & 0.9374 \\
$\Delta T_{T W}$ & 0.6309 & 0.8038 \\
\hline
\end{tabular}

and $\mathrm{CW}$ temperatures is the $\mathrm{CW}$ flowrate and that the plant duty and ambient temperature have significant disturbance effects. Figure 7 confirms how the change in TW flow influences the TW differential temperature. Also worth noting from Figures 7 and 9 is the non-linearity in the power when switching pumps due to the inclusion of the pump power curves as opposed to simply using the rated power. Some interesting dynamics are also observed such as the inverse response seen in the TW differential temperature when changing the plant duty.

\section{Discussions and Conclusion}

The model provides insight into the effects of the different components on the process variables and illustrates the non-linearities and interactions of the system. It is easily customisable in terms of the number of equipment in the system and provides a robust simulation platform. Figures 6 to 9 reveal valuable behavioural information of the system and illustrates that the system responds as expected and also reveals some interesting dynamics and interactions.

The use of an optimisation algorithm for model parameter estimation greatly improves model quality as can be seen in Table 3. The state-space model form described in Section 5 provides a convenient starting point for control and optimisation solutions as well as simulation.

The correlation coefficients shown in Table 3 indicate an adequate accuracy for the purposes of this simplified model keeping in mind the objectives of the model are firstly to provide a simple plant simulation platform and secondly to 
provide a starting point for the formulation of a control/optimisation model. The main advantage of optimising the system would be a reduction in energy consumption by reducing the number of pumps and fans running during times where over-cooling is provided. It is difficult for an operator to gauge whether the process constraints will be honoured when switching pumps or CT fans. The model will allow the controller/optimiser to determine this and optimise the system while honouring the constraints.

\section{Acknowledgements}

Thanks to Sasol for making data available for the model validation and allowing this work to be published. Thanks to Mr. Mark Congiundi for his assistance in validating the model equations and his advice in general.

\section{References}

[1] C. J. Muller, I. K. Craig, Cooling water system modelling for control and energy optimisation purposes, in: Proceedings of the 19th IFAC World Congress, Cape Town, IFAC, 2014, pp. 3973-3978, 10.3182/20140824-6ZA-1003.01030.

[2] I. K. Craig, et al., Control in the process industries, in: T. Samad, A. Annaswamy (Eds.), The Impact of Control Technology, IEEE Control Systems Society, 2011, available at http://www.ieeecss.org/main/IoCT-report.

[4] R. Inglesi-Lotz, J. N. Blignaut, South Africa's electricity consumption: A sectoral decomposition analysis, Applied Energy 88 (12) (2011) 4779-4784.

[5] C. J. Muller, I. K. Craig, N. L. Ricker, Modelling, validation, and control of an industrial fuel gas blending system, Journal of Process Control 21 (6) (2011) 852-860. 
[6] N. L. Ricker, C. J. Muller, I. K. Craig, Fuel gas blending benchmark for economic performance evaluation of advanced control and state estimation, Journal of Process Control 22 (6) (2012) 968-974.

[7] R. Saidur, N. A. Rahim, M. Hasanuzzaman, A review on compressed-air energy use and energy savings, Renewable and Sustainable Energy Reviews 14 (4) (2010) 1135-1153.

[8] M. S. Bhatt, Energy audit case studies I — steam systems, Applied Thermal Engineering 20 (3) (2000) 285-296.

[9] D. W. Green (Ed.), Perry's Chemical Engineers' Handbook, 4th Edition, McGraw-Hill, 1997.

[10] B. G. Lipták, Instrument Engineers' Handbook, 4th Edition, Vol. II: Process Control and Optimization, CRC Press, Florida, 2006.

[11] A. Bemporad, M. Morari, Control of systems integrating logic, dynamics, and constraints, Automatica 35 (3) (1999) 407-427.

[12] A. J. van Staden, J. Zhang, X. Xia, A model predictive control strategy for load shifting in a water pumping scheme with maximum demand charges, Applied Energy 88 (12) (2011) 4785-4794.

[13] X. Zhuan, X. Xia, Optimal operation scheduling of a pumping station with multiple pumps, Applied Energy 104 (2013) 250-257.

[14] S. Zhang, X. Xia, Optimal control of operation efficiency of belt conveyor systems, Applied Energy 87 (6) (2010) 1929-1937.

[15] D. E. Seborg, T. F. Edgar, D. A. Mellichamp, Process Dynamics and Control, 2nd Edition, Wiley, 2004.

[16] R. L. Daugherty, J. B. Franzini, Fluid Mechanics with Engineering Applications, 7th Edition, McGraw-Hill, 1977, pp. 524-526. 
[17] R. Stull, Wet-bulb temperature from relative humidity and air temperature, Journal of Applied Meterology and Climatology 50 (2011) 2267-2269.

[18] B. Matthews, I. K. Craig, Demand side management of a run-of-mine ore milling circuit, Control Engineering Practice 21 (6) (2013) 759-768.

[19] K. J. Hunt, Systems identification with genetic algorithms, in: IEE Colloquium on Genetic Algorithms for Control Systems Engineering, 1993, pp. $3 / 1-3 / 3$.

[20] P. J. Fleming, C. M. Fonseca, Genetic algorithms in control systems engineering: A brief introduction, in: IEE Colloquium on Genetic Algorithms for Control Systems Engineering, 1993, pp. 1/1-1/5.

[21] C. M. M. Fonseca, Multiobjective genetic algorithms with application to control engineering problems, Ph.D. thesis, Department of Automatic Control and Systems Engineering, University of Sheffield, Sheffield, UK (1995). 